\title{
O entendimento do direito à saúde: uma abordagem dos usuários do SUS no Distrito Federal
}

\author{
Understanding the right to health: a study of users of SUS in Federal District
}

\section{Rosa Shirley Peres da Silva ${ }^{1}$}

Resumo: Este estudo objetivou analisar a percepção dos usuários do SUS, no Distrito Federal, sobre o direito à saúde e o impacto desse entendimento na dinâmica da construção do Sistema. Foram realizadas entrevistas com 75 usuários, entre setembro e outubro de 2014. Como roteiro de pesquisa utilizou-se o método qualiquantitativo de abordagem descritiva exploratória. Para auxiliar a pergunta aberta utilizou-se a técnica do Discurso do Sujeito Coletivo (DSC). O entendimento de SUS como política criada para garantir o direito à saúde é substituído pela ideia de concessão do Estado. $O$ impacto desse entendimento na dinâmica da construção do sistema acontece pela baixa capacidade de organização e pouco conhecimento e participação no Conselho de Saúde. Foi possível concluir que o desconhecimento do direito à saúde compromete e enfraquece o processo de desenvolvimento do SUS, que se fundamenta no princípio da participação e do controle social.

Palavras-chave: Saúde, Direito à Saúde, Sistema Único de Saúde.

Abstract: This study aimed to analyze the users' perception of SUS in the Federal District, on the right to health and the impact of this understanding in the dynamics of the construction of the system. Interviews were conducted with 75 users, between September and October 2014. As a research roadmap it was used the quantitative and qualitative method of descriptive exploratory approach. To help the open question, the technique of the Collective Subject Discourse (CSD) was used. The understanding of SUS as a policy designed to ensure the right to health is replaced by the State granting idea. The impact of this understanding in the dynamics of system construction happens by low organizational skills and little awareness and participation on the Health Council. It was possible to conclude that that the ignorance of the right to health undermines and weakens the development process of SUS, which is based on the principle of participation and social control.

Keywords: Health, Right to Health, Unified Health System.

Resumén: Este estudio tuvo como objetivo analizar la percepción del SUS, el Distrito Federal, en el derecho a la salud y el impacto que la comprensión de la dinámica de la construcción del sistema. Se realizaron entrevistas con 75 usuarios, entre septiembre y octubre de 2014. Como una hoja de ruta de investigación utilizó el método cuantitativo y cualitativo de enfoque exploratorio descriptivo. Para ayudar a pregunta abierta utilizó la técnica del Discurso del Sujeto Colectivo (CSD). Entender SUS como una política destinada a garantizar el derecho a la salud se sustituye por la idea del Estado conce-

\footnotetext{
${ }^{1}$ Graduada em Biomedicina pelo Centro Universitário de Brasília (UniCeub). Pós-graduada em Direito Sanitário pela Fundação Oswaldo Cruz em Brasília - Fiocruz Brasília. Brasília, Brasil. E-mail: rosashirley@yahoo.com.br.
} 
dente. El impacto de este conocimiento en el sistema de construcción de la dinámica pasa por la capacidad de organización bajos y poco conocimiento y la participación en el Consejo de Salud. Se concluyó que la falta de derecho a compromisos de salud y debilita el proceso de desarrollo del SUS, que se basa en principio de la participación y el control

Palabras-llave: Salud, Derecho a la Salud, Sistema Único de Salud.

\section{Introdução}

O processo de construção da cidadania brasileira foi fortalecido após a conquista do direito à saúde na Constituição Federal (CF) de 1988. A partir desse momento, a saúde passou a ser direito de todos e dever do Estado, ganhando nova perspectiva. Um direito alicerçado também nas causas sociais, definidas como fatores determinantes e condicionantes de saúde, que são responsáveis pelo bem estar físico, mental e social do indivíduo e da coletividade.

Os ideais de participação e controle social saíram do contexto de utopia e ganharam força com os movimentos sociais; logo, não poderiam ser perdidos, mas garantidos também como um direito. Todas essas conquistas e muitas outras só foram possíveis a partir da forte iniciativa popular da época.

Durante o regime de ditadura militar (1964-1985) a concepção de controle social estava sob o domínio do Estado, o modelo de saúde era centralizado e havia uma queda crescente das ações voltadas à saúde pública. Essas práticas acentuavam cada vez mais a desigualdade social. Após a queda, a concepção de controle social passou por um período de transição e as políticas públicas deixaram de ser domínio do Estado e passaram ao controle da população (1).

O Movimento de Reforma Sanitária Brasileira, a partir da consciência do direito à saúde e contrário ao modelo político ditatorial, conduziu e estimulou novas mudanças sociais, como a defesa da participação e do controle da sociedade na gestão das políticas públicas. Essa participação foi positivada pela CF de 1988 e, posteriormente, pelas Leis 8.080/90 (2) e 8.142/90 (3), sendo a última, responsável por instituir as instâncias de participação da comunidade na gestão do SUS, as conferências e os conselhos de saúde, que têm a missão de „atuar na formulação e proposição de estratégia no controle da execução das políticas de saúde, inclusive em seus aspectos econômicos efinanceiros". 
Desse modo, o Sistema Único de Saúde (SUS) é uma conquista fundamentalmente de iniciativa e participação social, que, em sua essência, possibilita aos usuários opinarem e, de forma efetiva, participarem do processo de construção, implementação e gestão dos serviços públicos.

Com efeito, participação é a conquista humana principal, tanto no sentido de ser mais do que nunca uma conquista [...] quanto no sentido de ser mais humana imaginável - porque é especificamente a forma de realização humana. [...] a história que vale a pena é aquela participativa, ou seja, com o teor menor possível de desigualdade, de exploração, de mercantilização, de opressão (4).

Pedro Demo (5) afirma que a participação social colabora com o fortalecimento da sociedade nas decisões políticas do país, e que deve ser considerada um meio para mudança nas relações de poder na sociedade, buscando uma maior equidade e justiça social. Participação social é, portanto, conquista e não concessão. É o exercício democrático conquistado por uma comunidade organizada e que promove a realização participativa.

Dallari (6) destaca o entendimento da sociedade perante o direito à saúde, uma vez que isso permite o fortalecimento da municipalização dos serviços de saúde, na qual a comunidade passa a ser participante do processo de construção da saúde, buscando melhorar os serviços e o alcance do bem estar social.

Diante disso, a opinião e o conhecimento do usuário sobre o direito à saúde, sobre o próprio SUS e ainda sobre os canais utilizados para inseri-lo no Sistema, fortalecem essa participação e o exercício da cidadania. Fornecem, ainda, conceitos e atitudes associadas à atenção recebida, sendo esses dados úteis para a melhoria dos serviços e para o cumprimento do direito à saúde.

Nesse contexto, a pesquisa buscou compreender o conhecimento dos usuários sobre o SUS e o direito à saúde, e de que forma esse entendimento repercute na dinâmica da participação social, visto que esta é à base da construção do sistema de saúde brasileiro.

\section{Metodologia}

Foi realizado um estudo exploratório e descritivo, com abordagem qualitativa e quantitativa. A dicotomia entre as pesquisas qualitativas e quantitativas é, por vezes, analisada por alguns autores de forma restritiva e contrastante; porém, é sabido que 
essa opinião já não se adequa mais ao campo de pesquisas acadêmico-científicas, uma vez que existem estudos relevantes que mesclam os dois conceitos.

Segundo Lefèvre (7), os conceitos de quantidade e qualidade não são excludentes, como muitos afirmam, mas sim, complementares. Partindo dessa premissa, optou-se por essa dupla abordagem, uma vez que se pretende dissertar sobre a pesquisa qualitativa e sua correlação com as Representações Sociais como produto do Discurso do Sujeito Coletivo (DSC).

A pesquisa foi desenvolvida com 75 usuários do SUS no Distrito Federal (DF), por meio de entrevistas. A seleção do campo de pesquisa foi feita de forma aleatória, em praças públicas e ruas de diferentes regiões administrativas do DF. Levou-se em consideração o livre acesso aos entrevistados e o número expressivo de usuários que circulam nesses locais.

Foram utilizados como critérios de inclusão: possuir como único meio de acesso à saúde o SUS (sem plano de saúde privado) e idade superior ou igual a 18 anos. Todos os participantes foram esclarecidos quanto aos objetivos da pesquisa. Aqueles que consentiram em participar assinaram o Termo de Consentimento Livre e Esclarecido, tendo suas identidades mantidas em sigilo, com a segurança pessoal e social garantidas.

Os dados foram coletados nos meses de setembro e outubro de 2014, por meio de questionário com 11 questões (Quadro 1). 


\section{Quadro 1 - Formulário de entrevistas}

\begin{tabular}{|c|c|}
\hline № & Pergunta \\
\hline 1. & O que é saúde para você? \\
\hline 2. & $\begin{array}{l}\text { Você sabe que significa a sigla SUS? } \\
\text { ( ) Sim: } \\
\text { ( ) Não }\end{array}$ \\
\hline 3. & $\begin{array}{l}\text { Você sabe qual a Lei que garante a promoção, proteção e recuperação da saúde bem como sua } \\
\text { organização e o funcionamento? } \\
\text { ( ) Sim, qual? } \\
\text { ( ) Não }\end{array}$ \\
\hline 4. & $\begin{array}{l}\text { Você utiliza algum meio para reclamação, denúncia ou sugestões na saúde? } \\
\text { ( ) Sim, qual? } \\
\text { ( ) Não }\end{array}$ \\
\hline 5. & $\begin{array}{l}\text { Onde obtêm, preferencialmente, informações sobre o atendimento de suas necessidades e seus } \\
\text { direitos em relação aos serviços de saúde? } \\
\text { Leio informativos da SES/DF ( ) } \\
\text { Pergunto a outras pessoas ( ) } \\
\text { Procuro a UBS/Hospital( ) } \\
\text { Através de agente comunitário de saúde ( ) } \\
\text { Radio e televisão ( ) } \\
\text { Não faço nada ( ) } \\
\text { Outros, qual: }\end{array}$ \\
\hline 6. & $\begin{array}{l}\text { Em relação aos serviços de saúde pública que já utilizou, você confia? } \\
\text { Sim ( ): confia totalmente ( ) confia muito ( ) Confia pouco ( ) } \\
\text { Não ( ) }\end{array}$ \\
\hline 7. & $\begin{array}{l}\text { Você acha que as leis são de fácil compreensão? } \\
\text { ( ) Sim } \\
\text { ( ) Não }\end{array}$ \\
\hline 8. & $\begin{array}{l}\text { Você possui acesso às leis de saúde? } \\
\text { ( ) Sim, qual meio utiliza para ter acesso? } \\
\text { ( ) Não }\end{array}$ \\
\hline 9. & $\begin{array}{l}\text { Você faz parte de alguma organização de saúde ou movimento social da saúde? } \\
\text { ( ) Sim, qual? } \\
\text { ( ) Não }\end{array}$ \\
\hline 10. & $\begin{array}{l}\text { Você sabe o que é um Conselho de Saúde e para que ele serve? } \\
\text { ( ) Sim } \\
\text { ( ) Não }\end{array}$ \\
\hline 11. & $\begin{array}{l}\text { Já participou de alguma reunião do Conselho de Saúde? } \\
\text { ( ) Sim, de que forma? } \\
\text { ( ) Não }\end{array}$ \\
\hline
\end{tabular}

Fonte: Elaboração da autora. 
As perguntas foram elaboradas com base na literatura do tema e tinham como objeto de interesse abordar os seguintes tópicos: o conceito de saúde; o SUS, informação em saúde e participação social no SUS.

Para análise, organização e interpretação dos dados coletados com as perguntas fechadas, foi utilizado o sistema de planilhas do Microsoft Office Excel, versão 2010. Para auxiliar a pergunta aberta, a ferramenta utilizada para análise foi o Software Qualiquantisoft, desenvolvido para a construção do Discurso do Sujeito Coletivo (DSC).

Criado e desenvolvido por Fernando Lefèvre e Ana Maria Lefèvre (7), o DSC é uma metodologia que possui a teoria da Representação Social como fundamento. A técnica consiste em coletar depoimentos e extrair de cada um deles três figuras metodológicas: expressões chaves, ideias centrais e ancoragens. Essas figuras se complementam e se assemelham, possibilitando a construção de um ou vários discursos-síntese, que são os Discursos do Sujeito Coletivo, o que permite compreender as opiniões, valores e representações do pensamento coletivo sobre determinado tema (8).

\section{Resultados e Discussão}

\section{Conceito de Saúde}

Com o objetivo de conhecer e analisar o conceito de saúde dos usuários utilizouse a seguinte questão aberta: O que é saúde para você?

A análise das diferentes opiniões dadas para a referida questão possibilitou a construção de um DSC que apresenta cinco ideias centrais associadas ao conceito de saúde: necessidade (a); bem estar e qualidade de vida (b); ausência de doença (c); serviço e atendimento (d); e, insatisfação (e). Assim, obteve-se o seguinte DSC:

Para mim saúde é fundamental, é prioridade e sem ela é impossível viver bem. $\mathrm{Na}$ verdade, acho que envolve tudo, sabe (a)? O bem estar físico, espiritual, mental, social e até o econômico, porque a gente precisa de dinheiro também para poder viver bem. É estar de bem com a vida, ter qualidade de vida e cuidar do próprio corpo, comendo bem e fazendo atividade física (b). É também não ficar doente, não precisar ir ao médico e nem de remédios (c) e a gente precisa se manter bem informado de tudo porque saúde é um direito e um serviço que a gente precisa, né?... É chegar ao hospital e ser bem atendido, sair recuperado e não pior do que entrou (d). Mas está difícil ter saúde aqui, nesses hospitais, os serviços não funcionam e a gente não tem acesso à saúde. Então, saúde para mim é um descaso e muita tristeza. A saúde tem que ser cuidada e não desvalorizada (e)". 
As ideias apresentadas no discurso como necessidade (a), bem estar e qualidade de vida (b) se assemelham ao adotado pela OMS, pois apresentam visão ampliada e coletiva de saúde. Devem-se considerar, portanto, os aspectos socioeconômicos e as ações do Estado para promoção de saúde e prevenção de doenças, ou seja, o dever de garantir o direito à saúde.

A ideia presente no discurso de associar saúde à ausência de doença (c) é considerada ultrapassada, por ser muito individualista e ampliar apenas o enfoque "curativista" de saúde. É possível apreender, ainda, a busca do indivíduo por autonomia de saúde quando afirma: "não precisar ir ao médico e nem de remédios (c)".

Esse entendimento pode levar em conta a associação positiva do reconhecimento de responsabilidade individual. Conforme explicitado no art. $2^{\circ}$ da lei 8080/90 (2), „0 dever do Estado, na garantia da saúde, não exclui o das pessoas (...". Mas, pode ter também um valor negativo, quando se associa médico e doença - reforçando a condição mecanicista da saúde - ou serviços de saúde de baixa qualidade e condição de saúde.

Nas ideias associadas a serviço e atendimento (d) e insatisfação (e), nota-se, respectivamente, uma visão assistencialista e insegura vinculada ao conceito de saúde. O indivíduo resguarda sua saúde (c) pela falta de confiança e receio de depender do serviço.

Em ambos, é nítida a ausência de uma noção mais ampliada do que é ter saúde, direito à saúde e direito à assistência à saúde. Para Pacheco e Garbin (9), essa visão pulverizada do conceito influencia a percepção focal do usuário nas ações do Estado para a garantia da saúde da população, dificultando a conscientização de ator-social na luta pelo direito.

Diante disso, o processo de cidadania se enfraquece, uma vez que não há uma sólida apreensão do direito à saúde. Com isso, a participação não acontece de forma efetiva e o empoderamento ${ }^{2}$ é cada vez mais distante (10) (11).

\footnotetext{
${ }^{2} \mathrm{O}$ empoderamento (empowerment) pode ser entendido como a ampliação das possibilidades de controle, por um sujeito/população, dos aspectos significativos relacionados à sua própria existência, de acordo com a concepção do economista indiano Amartya Kumar Sem.
} 


\section{o sus}

O segundo questionamento abordou a compreensão do usuário a respeito da sigla SUS. As respostas indicaram que $88 \%$ dos entrevistados sabiam seu significado corretamente - $12 \%$ desconheciam o termo. Vale ressaltar que, dos $88 \%$ que conheciam a sigla, 8\% deram respostas aleatórias como: „coisa de saúde" e „cartão do hospital para atendimento".

Em pesquisa empreendida pelo Conselho Nacional de Secretários de Saúde (CONASS), em 2002, apenas 35\% dos entrevistados sabia o significado da sigla SUS, e esse percentual apresentava crescimento significativo se comparado com o mesmo levantamento em 1998, no qual o nível de acerto chegou a 25\% (12).

O aumento da divulgação de informações sobre as diversas ações e serviços promovidos pelo SUS justifica o aumento do entendimento da população diante da sigla que denomina o sistema de saúde brasileiro.

De acordo com Silva e Rasera (13), a sigla SUS ainda é pouco utilizada para se noticiar melhorias nos índices de saúde ou, até mesmo, como referência de serviços prestados. A construção negativa e a associação de problemas ligados à sigla SUS são vistas com mais frequência nos noticiários, o que contribui para a formação do SUS-problema.

A compreensão de cada letra que compõe a sigla SUS não garante o entendimento claro do seu significado como um todo. Os usuários, normalmente, associam o significado de cada letra para compor uma ideia do sistema. Esta ligação é individual e corresponde ao nível de familiaridade do termo e sua associação com algo préconcebido. Desse modo, sistema de saúde sugere uma variedade de ideias, como os critérios mencionados anteriormente. O SUS deve ser um termo entendido e apreendido pelos usuários em seu conjunto como um direito adquirido (14).

\section{A Lei Orgânica}

Quando perguntado sobre o conhecimento da Lei que garante a promoção, proteção, recuperação da saúde bem como sua organização e funcionamento, $80 \%$ dos entrevistados admitiram desconhecimento. Outros $20 \%$ afirmaram conhecer a lei, sendo que $16 \%$ conseguiram responder corretamente o número da mesma. 
A expressiva porcentagem de entrevistados que ignora a Lei Orgânica da Saúde reflete o desconhecimento do usuário que passa a entender o controle social como concessão do Estado, não como conquista.

\section{O acesso e a compreensão das leis}

Dois fatores dificultam ainda mais esse processo: a dificuldade de compreensão e o acesso às leis de saúde. No primeiro caso, observou-se que $63 \%$ dos entrevistados alegaram que as leis não são de fácil compreensão. Verifica-se que a comunicação, no caso a lei, é comprometida, já que o público a quem se destina não consegue interpretá-la.

Facilitar o entendimento dos textos legislativos é uma maneira de aproximar a população e favorecer o cumprimento das leis e a aplicação de sanções [...]. A transparência do sentido dos atos normativos, bem como sua inteligibilidade, são requisitos do próprio Estado de Direito: é inaceitável que um texto legal não seja entendido pelos cidadãos (15).

No segundo fator, $54,6 \%$ dos entrevistados alegaram não possuir acesso às leis de saúde. Esse dado remete ao desconhecimento e à dificuldade do usuário em buscar tais informações em fontes específicas. Dos $45,4 \%$ que possuem acesso às leis, $36 \%$ utilizam a internet como canal de acesso. Neumann (16) defende o uso de meios populares, modernos e de amplo acesso para motivar o exercício da cidadania. A aproximação da linguagem desses meios com a sociedade local fortalece o controle social pela troca de conhecimento.

O controle social é a expressão mais viva da participação da sociedade nas decisões tomadas pelo Estado no interesse geral, suas manifestações mais importantes são o cidadão e o usuário no centro do processo de avaliação, deixando o estado de ser o árbitro infalível do interesse coletivo, do bemcomum (17).

\section{Conscientização x Reivindicação}

A conscientização e a educação sanitária contribuem positivamente para a aquisição do direito à saúde, que ainda é tido como um elo fraco, principalmente pelos usuários mais vulneráveis do sistema. Fato esse, observado por Bosi e Affonso (11), ao verificarem que a fragilidade se estende ao direito como um todo, não apenas ao direito à saúde. 
Os relatos identificaram ainda uma descrença sobre a efetivação dos direitos para a massa da população; além, de uma divisão de poderes entre as classes mais ricas e mais pobres, que resulta na sensação de submissão e resignação.

Com relação à utilização de meios para reclamação, denúncia ou sugestões na saúde, $77 \%$ dos entrevistados disseram não utilizar quaisquer meios. Apenas $23 \%$ afirmaram utilizar algum meio. A partir da descrição dos meios, foi feita uma subdivisão em três categorias: Ouvidoria, Hospital e Outros (Tabela 1).

Tabela 1 - Resultado da questão 4 do formulário de entrevistas.

\begin{tabular}{ccc}
\hline Sim & $23 \%$ \\
\hline Ouvidoria & $12 \%$ \\
Hospital & $7 \%$ \\
Outros & $4 \%$ \\
\hline Não & $77 \%$ \\
\hline Total & $100 \%$ \\
\hline
\end{tabular}

Fonte: Elaboração da autora.

A porcentagem elevada e preocupante de usuários que não utilizam qualquer canal para reclamação, denúncia ou sugestões na saúde nos remete à falta de informação e insatisfação do usuário visando à modificação da sua situação de saúde. Os canais de interlocução são vistos pelos usuários como ineficazes, tornando-se um obstáculo para o próprio indivíduo e para o controle social.

A ideia previamente concebida de que o usuário é um aliado na construção do SUS fica perdida, à medida que a sensação de desamparo e desânimo se torna sua consciência sanitária. Associado a isso, a realidade da mudança é algo distante ao usuário que se sente excluído do poder e depende de outro para exercê-lo. É necessário, portanto, que o usuário se enxergue como peça-chave para a resolução dos problemas, pois os vivencia diariamente, seja reclamando, denunciando ou sugerindo soluções éticas (11).

Outro dado importante é referente ao uso da ouvidoria, que compôs as falas de $12 \%$ dos usuários que a utilizam como canal de participação. O objetivo da ouvidoria é vincular o usuário e o gestor do SUS na busca da melhoria da qualidade de serviços prestados. Essa estratégia de controle e participação social auxilia os gestores na direção, melhoria e desenvolvimento de práticas para atender a população (18). 
Ainda assim, é necessário melhorar os resultados desse instrumento para envolver cada vez mais o usuário não-organizado, ou seja, aquele que necessita enxergar as mudanças advindas do uso dos meios de interlocução para que o nível de confiança no sistema aumente.

\section{Nível de confiança}

Foi avaliado o nível de confiança do usuário em relação aos serviços de saúde pública (Tabela 2).

Tabela 2 - Resultado da questão 6 do formulário de entrevistas

\begin{tabular}{lc}
\hline Sim & $72 \%$ \\
\hline Totalmente & $12 \%$ \\
Muito & $16 \%$ \\
Pouco & $41 \%$ \\
Não soube & $3 \%$ \\
descrever & $28 \%$ \\
\hline Não & $100 \%$
\end{tabular}

Fonte: Elaboração da autora.

A maioria dos usuários confia nos serviços (72\%). Ao passo que, $41,3 \%$ dos participantes alegaram confiar pouco nos serviços.

Segundo Valentim e Kruel (19), a confiança é uma construção. Vários fatores complementam e influenciam o seu nível como: acontecimentos anteriores, realidade coletiva, emoções e sentimentos que a envolvem, falta de informação, reciprocidade, observação do comportamento e a cooperação. Todos esses fatores se aplicam no caso da saúde, onde o grau de confiabilidade nos serviços está relacionado com os recursos físicos, tecnológicos e humanos, principalmente com relação aos médicos.

Logo, quando o usuário se sente negligenciado e a situação de descaso se configura, além do grau de confiança diminuir, os serviços de saúde são vistos como um favor, não como exercício de direito adquirido, o que pode explicar a elevada porcentagem observada dos que confiam pouco nos serviços. 
Santos et al. (18), baseados na teoria do "Capital Social", avaliaram a relação entre Capital Social e funcionamento satisfatório do SUS em duas cidades do Rio Grande do Sul. Capital Social. Os resultados obtidos na pesquisa mostraram quanto maior for o grau de confiança entre os cidadãos e as possibilidades de associação, maior será o Capital Social. Assim, o Capital Social facilita o controle social, possibilitando o melhor desempenho das ações do Estado.

\section{Das informações}

Diante do quadro apresentado, somada a pouca confiança nos serviços prestados pelo SUS e na perspectiva de que isso afeta o vínculo entre o usuário e o sistema, o resultado é o desinteresse. Se equacionássemos esse fenômeno teríamos: Desinteresse + Falta de informação = Reclamação.

Desse modo, foi analisada a obtenção de informações, por parte do usuário, sobre o atendimento de suas necessidade e seus direitos em relação aos serviços de saúde (Tabela 3).

Tabela 3 - Resultado da questão 5 do formulário de entrevistas

\begin{tabular}{lc}
\hline Leio informativos da SES/DF & $8,3 \%$ \\
Pergunto a outras pessoas & $19,4 \%$ \\
Procuro a UBS/Hospital & $51,4 \%$ \\
Através de agente comunitário de saúde & $5,5 \%$ \\
Rádio e televisão & $7 \%$ \\
Não faço nada & $4,2 \%$ \\
Outros & $4,2 \%$ \\
Total & \\
\hline
\end{tabular}

Fonte: Elaboração da autora. 
Nota-se, a partir dos dados, que a maioria dos usuários obtém suas informações diretamente na Unidade Básica de Saúde (UBS) ou no hospital, ou seja, a porta de entrada do sistema se configura nessas duas frentes.

Dos outros dados obtidos, $19,4 \%$ dos usuários obtém informações sobre o atendimento de suas necessidades por meio da confiança depositada nas experiências mencionadas por outros usuários. Desse modo, a referência de atendimento de um se torna a avaliação de outro, e essa influência será refletida no momento de busca de assistência.

Um dos princípios que compõe a Lei 8080/90 (3), (art. $7^{\circ}$ ) é a "divulgação de informações quanto o potencial dos serviços de saúde e a sua utilização pelo usuário". No presente estudo, observou-se o uso de rádio e televisão (7\%) como fonte de informações.

Para Martins (13), os diferentes modos de percepção da comunicação podem refletir em diferentes modos de intervenção na realidade. Dependendo de como o papel da comunicação for abordado na sociedade, pode favorecer ou dificultar a participação. O favorecimento pode ocorrer, no caso da saúde, à medida que fornece informações sobre direitos e fortalece o vínculo entre usuário e sistema, melhorando a percepção da participação popular nas políticas públicas.

Outros dados que merecem atenção são: o uso de informativos da Secretaria de Saúde $(8,3 \%)$, e a obtenção de informações por meio dos agentes comunitários de saúde (5,5\%). Esses dois importantes mecanismos de educação e comunicação em saúde devem ser trabalhados de forma a promover as informações aos usuários e fomentar o interesse pelas ações e pelo direito à saúde.

A respeito dos agentes de saúde, são os atores mais próximos da comunidade e conhecem a realidade das regiões nas quais estão inseridos. Podemos, então, considerá-los como educadores populares, como colaboradores da promoção de saúde, atuando na difusão e controle de informações. As atividades desses profissionais possuem caráter pedagógico e, quanto mais próxima estiver a comunicação entre usuário e agente, mais favorecida será a consciência e a ação da própria comunidade. A partir daí se alcançarão resultados mais promissores na atenção básica e na participação social. 
Albuquerque e Stotz (20) afirmam que a educação popular se insere no contexto da participação popular, pois „é também um compromisso político com as classes populares, com a luta por condições de vida e de saúde, pela cidadania e pelo controle social".

[...] no momento em que atores sociais tomam consciência das causas mais profundas dos problemas de saúde e das relações sociais que os permeiam, podem apontar para a luta social de forma mais consequente, ficando também mais comprometidos com a saúde da comunidade. [...] Lideranças, profissionais e agentes comunitários de saúde estão diretamente envolvidos nesse processo, estimulados a lutar pela saúde da comunidade e compelidos a buscar na própria comunidade formas de resolver e minorar algumas questões de saúde que não podem e nem devem esperar só pelo Estado.

O preparo para essa atividade é de suma importância para os resultados sobre as condições da região assistida e, para que as atividades de educação não se esgotem em programas ocasionais ou de epidemias, visto que a educação é um dos instrumentos de construção da cidadania.

\section{Conselhos de Saúde}

Foi analisado o conhecimento do usuário sobre os Conselhos. O resultado dessa análise se deu a partir de três questionamentos fundamentais: organização, conhecimento e participação (Quadro 2).

Quadro 2 - Resultado das questões número 9, 10 e 11 do formulário de entrevistas

\begin{tabular}{|l|l|c|c|}
\hline \multirow{2}{*}{ Objeto de estudo } & \multicolumn{1}{|c|}{ Perguntas } & \multicolumn{1}{|c|}{ Respostas } \\
\cline { 3 - 4 } & & Sim & Não \\
\hline Organização & $\begin{array}{l}\text { Faz parte de movimento/organização } \\
\text { de saúde? }\end{array}$ & $4 \%$ & $96 \%$ \\
\hline Conhecimento & $\begin{array}{l}\text { Sabe o que é um Conselho de Saúde } \\
\text { e sua função? }\end{array}$ & $24 \%$ & $76 \%$ \\
\hline Participação & $\begin{array}{l}\text { Participou de alguma reunião do } \\
\text { Conselho? }\end{array}$ & $3 \%$ & $97 \%$ \\
\hline
\end{tabular}

Fonte: Elaboração da autora. 
Sob o quesito organização, foi observado que $96 \%$ dos usuários não fazem parte de qualquer movimento ou organização de saúde.

O grau de confiança entre os cidadãos pode gerar mobilização e atuação coletiva pelo acúmulo de capital social e isso contribui para a consolidação da consciência cívica.

Ora, se o SUS é uma política pública de caráter participativo, essa fragilidade associativa, representada pelos $4 \%$ que se organizam, somada à falta de cultura cívica, identificada nas respostas de $96 \%$ dos usuários, só enfraquece e desconstrói a confiança, tanto no direito social à participação quanto no direito à saúde, visto que ambos se complementam (21) (22).

A falta de organização social se reflete nos dois outros aspectos analisados: conhecimento e participação no conselho. Explorando esse dois dados, em conjunto, percebemos que $24 \%$ dos entrevistados conhecem o Conselho de Saúde, número considerado razoável; porém, dessa porcentagem, apenas 3\% já participaram de alguma reunião do Conselho. Esses números se confrontam com os $76 \%$ que desconhecem a instância de controle social do SUS, e com os $97 \%$ que nunca participaram de qualquer reunião nesse espaço.

O Conselho de Saúde é um ambiente de pactuação, de controle e de participação entre os representantes da saúde (governo, prestadores de serviços, profissionais de saúde e usuários). A exigência legal de que a composição desse espaço se dê de forma paritária, sendo $50 \%$ de usuários e $50 \%$ dos demais segmentos, consolida o propósito de que o usuário deve ser 0 ator do sistema, pois enfrenta diretamente os problemas dos serviços oferecidos em sua realidade social (23).

Por fim, é possível afirmar que a falta de conhecimento dos usuários e de participação nos conselhos, influencia negativamente no processo de construção do SUS, principalmente no que se refere ao direito à saúde. É necessário, portanto, que se efetive e consolide, de fato, essa participação, e que a mesma acompanhe os processos evolutivos da sociedade, posto que isso seja condição fundamental para a realização da saúde (24) (25). 


\section{Considerações finais}

Foi constatado que, cada vez mais, tem-se perdido, no sentido de efetividade, o que se positivou: o anseio por uma sociedade mais equânime, detentora de seus direitos e deveres, consciente e que exerce o controle social de forma transformadora.

O entendimento do SUS como política criada para garantir o direito à saúde é substituído pela ideia de concessão do Estado. No imaginário do usuário, o SUS é um sistema carente e não está associado à sua capacidade de exercer o direito adquirido. O controle social parece estar cada vez mais subordinado ao Estado, não o contrário.

Verificou-se, ainda, que o desconhecimento das leis na área da saúde e a falta de consciência política e sanitária promovem a sensação de resignação e submissão da situação de saúde. Quando o usuário se sente negligenciado e o grau de confiança no SUS diminui, os serviços de saúde são vistos como favor e o usuário acaba por pedir um direito que já possui.

Além disso, a baixa capacidade de organização, o pouco conhecimento e participação no Conselho de Saúde - que se apresenta distante e cheio de regras ao usuário não organizado - só enfraquece e desconstrói a confiança, tanto no direito social à participação quanto no direito à saúde, visto que ambos se complementam.

Diante de todas essas questões, torna-se necessário resgatar os valores e ideais de construção do SUS, desenvolver os valores coletivos da política de saúde e empoderar os representantes do sistema, especialmente o usuário.

\section{Referências Bibliográficas}

1 Amorim CR et al. Participação e Mobilização Social no SUS: Entraves, Desafios e Perspectivas. Revista APS [Internet]. 2012 [Acesso em 20 jul 2014], 15(3): 294-298. Disponível em http://pesquisa.bvsalud.org/portal/resource/pt/lil-655251.

2 Brasil. Lei no 8080/90, de 19 de setembro de 1990. Dispõe sobre as condições para a promoção, proteção e recuperação da saúde, a organização e o funcionamento dos serviços correspondentes e dá outras providências. Diário Oficial [da] República Federativa do Brasil [Internet]. Brasília, 20 set 1990 [Acesso em 08 set 2014]. Disponível em: http://www.planalto.gov.br/ccivil 03/Leis/L8080.htm 
3. Brasil. Lei $n^{\circ} 8142 / 90$, de 28 de dezembro de 1990. Dispõe sobre a participação da comunidade na gestão do Sistema Único de Saúde (SUS) e sobre as transferências intergovernamentais de recursos financeiros na área da saúde e dá outras providências. Diário Oficial [da] República Federativa do Brasil [Internet]. Brasília, 31 dez 1990 [Acesso em 08 set 2014]. Disponível em:

http://www.planalto.gov.br/ccivil 03/Leis/L8142.htm.

4 Demo, Pedro. Pobreza Política: Polêmicas do nosso tempo. São Paulo: Autores Associados; 1996.

5 Demo,P. Participação é Conquista: noções de política social participativa. São Paulo: Cortez; 1988.

6 Dallari DA. O Renascer do direito: direito e vida social, aplicação do direito, direito e política. São Paulo: Saraiva; 1996.

7 Lefevre F, Lefevre AMC. O Discurso do Sujeito Coletivo. Um novo enfoque em pesquisa qualitativa (Desdobramentos). Caxias do Sul: Educs; 2003

8 Figueiredo MZA, Chiari BM, Goulart BNG. Discurso do Sujeito Coletivo: uma breve introdução à ferramenta de pesquisa qualiquantitativa. Distúrbios da Comunicação [Internet], 2013 [Acesso em 28 set 2014], 25(1): 129-136. Disponível em http://revistas.pucsp.br/index.php/dic/article/view/14931.

9. Pacheco Filho AC, Garbin CAS. A saúde e seu direito sob o olhar do usuário. Revista Brasileira de Pesquisa em Saúde [Internet]. 2010 [Acesso em 04 set 2014], 12(3): 39-45, 2010. Disponível em http://periodicos.ufes.br/RBPS/article/view/825.

10 Bartolomei CEF, Carvalho MS de, Delduque MC. A Saúde é um Direito! Saúde em Debate [Internet]. 2003 [Acesso em 08 set 2014], 27(65): 184-191. Disponível em http://bases.bireme.br/cgi-

bin/wxislind.exe/iah/online/?IsisScript=iah/iah.xis\&nextAction=Ink\&base=LILACS\&expr Search=394022\&indexSearch=ID\&lang=i

11 Bosi MLM, Affonso KC. Cidadania, participação popular e saúde: com a palavra, os usuários da Rede Pública de Serviços. Cadernos de Saúde Pública [Internet]. 1998 [Acesso em 04 de set 2014], 14 (2): 355-365. Disponível em http://www.scielo.br/scielo.php?script=sci arttext\&pid=S0102311X1998000200020\&ln $\mathrm{g}=\mathrm{en} \& \mathrm{nrm}=\mathrm{iso}$.

12 Brasil. Conselho Nacional de Secretários de Saúde - CONASS. A saúde na opinião dos brasileiros/Conselho Nacional de Secretários de Saúde. Brasília, 2003.

13Silva GM, Rasera EF. A construção do SUS-problema no jornal Folha de S. Paulo. História, Ciências, Saúde-Manguinhos [Internet]. 2014 [Acesso em 23 out 2014], 21(1): 61-76. Disponível em http://www.scielo.br/scielo.php?script=sci arttext\&pid=S0104$\underline{59702014000100061 \& \operatorname{lng}=\mathrm{en} \& \mathrm{nrm}=\text { iso }}$ 
14 Paim, J. O que é o SUS? Rio de Janeiro: Fiocruz; 2009.

15 Guimarães LHP. A simplificação da linguagem jurídica como instrumento fundamental de acesso à justiça. Publicatio UEPG: Ciências Humanas, Linguística, Letras e Artes [Internet]. 2012 [Acesso em 23 out 2014], 20(2): 173-184. Disponível em http://www.revistas2.uepg.br/index.php/humanas/article/view/4270.

16 Neumann ZA. Controle Social e Cidadania. Revista do TCU [Internet]. 2004 [Acesso em 01 nov 2014], 1(102): 9-18. Disponível em: http://portal3.tcu.gov.br/portal/pls/portal/docs/2054642.PDF.

17. Crevelim MA, Peduzz M. Participação da comunidade na equipe de saúde da família: é possível estabelecer um projeto comum entre trabalhadores e usuários? Ciência e Saúde coletiva [Internet]. 2005 [Acesso em 08 ago 2014], 10(2): 323-331. Disponível em http://www.scielo.br/scielo.php?script=sci arttext\&pid=S141381232005000200010\&ln $\mathrm{g}=\mathrm{en} \& \mathrm{nrm}=\mathrm{iso}$.

18 Santos CC da SS, Bastos RL. Participação Social: A Construção da Democracia na Saúde Brasileira. Revista Brasileira de Pesquisa em Saúde, Ceará [Internet]. 2011 [Acesso em 18 jul 2014], 24(3): 266-273. Disponível em http://pesquisa.bvsalud.org/portal/resource/pt/lil-602540.

19 Valentim IVL, kruel AJ. A importância da confiança interpessoal para a consolidação do Programa de Saúde da Família. Ciência \& Saúde Coletiva [Internet]. 2007 [Acesso em 28 out 2014], 12(3): 777-788. Disponível em http://www.scielo.br/scielo.php?script=sci arttext\&pid=S141381232007000300028\&ln $\mathrm{g}=\mathrm{en} \& \mathrm{nrm}=\mathrm{iso}$.

20 Albuquerque PC de, Stotz EN. A educação popular na atenção básica à saúde no município: em busca da integralidade. Interface-Comunicação, Saúde, Educação [Internet]. 2004 [Acesso em 23 out 2014], 8(15): 259-274. Disponível em http://www.scielo.br/scielo.php?script=sci arttext\&pid=S141432832004000200006\&ln $\mathrm{g}=\mathrm{en \& nrm}=\mathrm{iso}$

21 Guizardi FL, Pinheiro R. Dilemas culturais, sociais e políticos da participação dos movimentos sociais nos Conselhos de Saúde. Ciência \& Saúde Coletiva [Internet]. 2006 [Acesso em 16 set 2014], 11(3): 797-805, 2006. Disponível em http://www.scielo.br/scielo.php?script=sci arttext\&pid=S141381232006000300027\&ln $\mathrm{g}=\mathrm{en} \& \mathrm{nrm}=$ iso.

22 Labra ME, Figueiredo JS. Associativismo, participação e cultura cívica. O potencial dos conselhos de saúde. Ciência \& Saúde Coletiva [Internet]. 2002 [Acesso em 1 out 2014], 7(3): 537-547. Disponível em 
http://www.scielo.br/scielo.php?script=sci arttext\&pid=S141381232002000300011\&ln $\mathrm{g}=\mathrm{en \&} \mathrm{nrm}=\mathrm{iso}$

23 Assis MMA. O Processo de construção do controle social no Sistema Único de Saúde e a gestão nos espaços institucionais. Saúde em Debate [Internet]. 2003 [Acesso em 08 set 2014], 27(65): 324-335. Disponível em http://bases.bireme.br/cgibin/wxislind.exe/iah/online/?IsisScript=iah/iah.xis\&nextAction=Ink\&base=LILACS\&expr Search $=394034$ \&indexSearch $=$ ID\&lang $=p$

24 Conserva AM et. al. Participação social na construção do SUS: uma análise à luz da experiência brasileira. Cadernos Ibero-americanos de Direito Sanitário [Internet]. 2014 [Acesso em 10 nov 2014], 3(2): 1-9. Disponível http://www.cadernos.prodisa.fiocruz.br/index.php/cadernos/article/view/13.

25 Coelho JS. Construindo a Participação Social no SUS: um constante repensar em busca de equidade e transformação. Saúde e Sociedade [Internet]. 2012 [Acesso em 20 ago 2014], 21(1): 138-151. Disponível em:

http://www.revistas.usp.br/sausoc/article/view/48776.

Recebido para publicação em 22 de janeiro de 2015. Admitido para publicação em 02 de julho de 2015. 